\title{
Competência midiática em crianças de 9 a 12 anos em cenários brasileiros
}

Media competence in children aged 9 to 12 in Brazilian settings

Competencia mediática em niños de 9 a 12 años em escenarios brasileños

DOI: https://doi.org/10.1590/1809-5844202111

\section{Márcia Barbosa da Silva ${ }^{1}$}

https://orcid.org/0000-0002-7635-963X

\section{Gabriela Borges ${ }^{2}$}

https://orcid.org/0000-0002-0612-9732

\section{Mônica Fantin ${ }^{3}$}

https://orcid.org/0000-0001-7627-2115

\section{Maria Alzira Almeida Pimenta ${ }^{4}$}

https://orcid.org/0000-0002-5775-5856

\section{Ignácio Aguaded ${ }^{5}$}

https://orcid.org/0000-0002-0229-1118

${ }_{1}^{1}$ (Universidade Estadual de Ponta Grossa, Setor de Ciências Humanas, Letras e Artes, Departamento de Pedagogia. Ponta Grossa - PR, Brasil).

${ }_{2}^{2}$ (Universidade Federal de Juiz de Fora, Faculdade de Comunicação, Programa de Pós-Graduação em Comunicação. Juiz de Fora - MG, Brasil).

${ }^{3}$ (Universidade Federal de Santa Catarina, Centro de Ciências da Educação, Programa de Pós-Graduação em Educação. Florianópolis - SC, Brasil).

${ }^{4}$ (Universidade de Sorocaba, Programa de Pós-Graduação em Educação. Sorocaba - SP, Brasil).

5(Universidade de Huelva, Departamento de Pedagogía, Máster Internacional en Comunicación y Educación Audiovisual. Huelva, Espanha). 


\title{
Resumo
}

Este artigo apresenta os resultados da pesquisa "Competências midiáticas em cenários brasileiros e euroamericanos”, que teve como objetivo conhecer os níveis de competência midiática de crianças de 9 a 12 anos para que pesquisadores, formadores e decisores políticos possam atuar para promover o seu desenvolvimento. Foi realizada pela equipe brasileira da Red Interuniversitaria Euroamericana de Investigación en Competencias Mediáticas para La Ciudadanía (ALFAMED) e os dados coletados por meio de questionários aplicados em cinco regiões brasileiras. Os resultados indicam que a competência midiática, especialmente as dimensões processos de interação e ideologia e valores, ainda estão pouco desenvolvida, indicando a necessidade e a urgência de atenção de professores e especialistas.

Palavras-chave: Competência Midiática. Literacia midiática. Alfamed. Mídia-educação. Comunicação e Educação.

\begin{abstract}
This paper presents the findings of the research "Media Competences in Brazilian and EuroAmerican Settings", which aimed at analyzing media competence in children aged 9 to 12 to enable researchers, educators and policy-makers to promote their development. The study was carried out by the Brazilian team of the Euro-American Inter-University Research Network on Media Literacy for Citizenship (ALFAMED) and the data was collected through questionnaires applied in five Brazilian regions. Results indicate that media competence, particularly regarding interaction processes and ideology and values dimensions, is still underdeveloped, which indicates the urgent need for teachers and experts' attention.
\end{abstract}

Keywords: Media competence. Media literacy. Alfamed. Media Education. Communication and Education.

\section{Resumen}

Este artículo presenta los resultados de la investigación “Competencias mediáticas en escenarios brasileños y euroamericanos” que tuvo como objetivo comprender los niveles de competencia mediática de niños de 9 a 12 años para que investigadores, formadores y responsables políticos puedan actuar para promover su desarrollo. Fue realizado por el equipo brasileño de la Red Interuniversitaria Euroamericana de Investigación en Competencias Mediáticas para La Ciudadanía (ALFAMED) y los datos recolectados a través de cuestionarios aplicados en cinco regiones brasileñas. Los resultados indican que la competencia mediática, en especial la dimensión de ideología y valores, aún está poco desarrollada, lo que indica la necesidad y urgencia de la atención de docentes y especialistas.

Palabras clave: Competencia mediática. Alfabetización mediática. Alfamed. Educación mediática. Comunicación y Educación.

\section{Introdução}

As transformações nas relações sociais intermediadas pela tecnologia digital têm impactado as culturas e as relações socioeconômicas. Nesse contexto, as discussões a 
respeito do papel exercido pela mídia na atualidade passam, entre outros aspectos, pelo entendimento da atuação da juventude nas redes sociais digitais. Se, por um lado, as crianças e jovens da atualidade já nasceram no mundo digital e midiático, por outro lado, os chamados “analfanautas”, cuja característica principal é ter uma performance digital razoável a avançada, mas carecer de desenvolvimento e mobilização de competências que lhes permitam "determinar a validade, pertinência e veracidade das informações que consomem, geram, difundem e/ou compartilham” (ROMERO RODRIGUEZ et al., 2016, p. 13), provocam questões sobre o que essa característica representa.

Com o intuito de contribuir para ampliar a compreensão desses processos, a equipe brasileira da Rede Alfamed ${ }^{1}$ (Rede Interuniversitária Euroamericana de Investigação em Competências Midiáticas para a Cidadania), composta pela Universidade Federal de Juiz de Fora (UFJF - coordenação), Universidade Estadual de Ponta Grossa (UEPG - vicecoordenação), Universidade de Brasília (UNB), Universidade Federal de Santa Catarina (UFSC), Universidade Federal do Triângulo Mineiro (UFTM) e Universidade de Sorocaba (UNISO), desenvolveu a pesquisa "Competências midiáticas em cenários brasileiros e euroamericanos”2 (2015-2019). O objetivo centrou-se em mapear os níveis de competência midiática de diferentes segmentos: crianças de 9 a 12 anos, jovens de 14 a 16 anos, universitários de 17 a 21, professores universitários e profissionais da comunicação a fim de propor ações de formação e estratégias para o desenvolvimento de políticas públicas.

O escopo teórico da pesquisa está baseado no conceito de competência midiática elaborado por Ferrés (2007) e Ferrés e Piscitelli (2012) e apresenta-se como uma ampliação da pesquisa realizada anteriormente (FERRÉS et al., 2011) na Espanha. Sob a coordenação da UFJF, cada universidade contribuiu com a pesquisa a partir de subprojetos que incluíam pelo menos dois segmentos, de acordo com as características dos grupos de pesquisa envolvidos. A partir dos resultados obtidos, os pesquisadores elaboraram propostas de ações de formação para desenvolver a competência midiática.

Neste artigo, apresentamos os resultados dos 502 questionários aplicados ao segmento de crianças de 9 a 12 anos pelas universidades UFJF, UEPG, UnB, UFSC e UNISO. O recorte realizado para este trabalho enfoca a análise dos níveis de competência midiática das crianças em cada uma das seis dimensões propostas por Ferrés e Piscitelli (2012), os quais foram cruzados com os dados do perfil dos participantes, tais como faixa etária, sexo, tipo de escola e formação em comunicação audiovisual e digital a fim de permitir uma reflexão sobre as carências encontradas e apontar pistas para o desenvolvimento de ações de formação docente e discente e fomento de estratégias de desenvolvimento de políticas públicas.

\footnotetext{
1 A Red Alfamed é composta por 19 países ibero-americanos e europeus (www.alfamed.org).

2 A pesquisa contou com financiamento do Conselho Nacional de Desenvolvimento Científico e Tecnológico (CNPq), por meio do Edital MCTI/CNPq/MEC/CAPES nº 14/2014 - Ciências Humanas e Ciências Sociais Aplicadas (Processo 449573/2014-1); da Fundação de Amparo à Pesquisa do Estado de Minas Gerais (FAPEMIG), por meio da chamada 01/2015 - Demanda Universal (Todos os domínios científicos) 2015 (Processo APQ CHE 002824-15); do Programa Universidade sem Fronteiras, da Secretaria de Ciência e Tecnologia do Estado do Paraná; da Universidade Federal de Juiz de Fora; e a elaboração desse artigo se inscreve no âmbito dos incentivos da Fundación Carolina por meio de seu programa de Professor Visitante.
} 


\section{Literacia midiática e o desenvolvimento de competências}

Diante do protagonismo das tecnologias digitais em nossas vidas, que pode ser sintetizado na expressão onlife (FLORIDI, 2017) para definir nossas atividades cotidianas, ainda precisamos de uma base conceitual moderna que nos ajude a compreender os seus impactos na sociedade e os desafios de viver em uma era hiper conectada, como diz o autor. Neste sentido, as práticas midiáticas e culturais relacionadas à produção e ao compartilhamento de conteúdos entre crianças e jovens nos desafiam a entendê-las e problematizá-las a partir de uma perspectiva crítica.

Há mais de 10 anos, Martin-Barbero (2008, p. 20) ressaltava que a tecnologia é “uma das metáforas mais potentes para compreender o tecido - redes e interfaces - de construção da subjetividade". No entanto, ao enfatizar a tecnologia como cultura, é importante entender que no contexto da cultura digital, as tecnologias não são "meros instrumentos" para auxiliar e/ou contribuir com certas práticas, mas "fundamentos estruturantes das práticas", como argumenta Pretto (2015). Para o autor, as tecnologias digitais são elementos de uma "nova escrita do contemporâneo" (PRETTO, 2019, p. 2).

Nessas escritas, computadores e celulares não são neutros, pois carregam valores e modos de uso implícitos. E apesar de certo grau de flexibilidade, noção de agência, experimentação e apropriação por parte de crianças e jovens, a ênfase num uso crítico e reflexivo das tecnologias digitais necessita da mediação. E para propiciar esta mediação, é fundamental atuar no sentido de desenvolver competências midiáticas.

Desde 1982, com a Declaração de Grünwald, a UNESCO vem assinalando a importância dos estudos em comunicação e educação, a partir da educação infantil, com o intuito de "desenvolver os conhecimentos, aptidões e atitudes que favoreçam o crescimento de uma consciência crítica e, consequentemente, de uma maior competência entre os utilizadores dos media eletrônicos e impressos" (UNESCO, 1982, p. 2). Indicando a necessidade de que esses estudos contribuam para o desenvolvimento da capacidade de análise crítica e expressão criativa. As declarações que se seguiram avançam nessas reflexões, dentre elas pode-se destacar a de Paris, que considera que a educação para a mídia deve "desenvolver habilidades para a análise crítica de mensagens, seja em notícias ou entretenimento, a fim de fortalecer as capacidades de indivíduos autônomos e usuários ativos"; respeitar a diversidade de culturas e os direitos humanos, contribuindo para o desenvolvimento de responsabilidade social (UNESCO, 2007, p. 1).

A literacia midiática é definida como a capacidade de acessar, analisar e avaliar o poder de imagens, sons e mensagens, assim como comunicar de forma crítica e criativa por meio das mídias disponíveis. Como indica uma das pioneiras neste campo, "a promessa da literacia midiática, certamente, é que ela pode fazer parte de uma estratégia para reposicionar o usuário de mídia - de passivo para ativo, de receptor para participante, de consumidor para cidadão” (LIVINGSTONE, 2004, p. 20). Dessa maneira, a literacia midiática estaria 
na base da formação para uma cidadania ativa e crítica Autores como Wilson et al. (2013), Pereira, Pinto e Moura (2015) e Buckingham (2019) também têm desenvolvido estudos a partir deste conceito.

Há um consenso de que a literacia midiática precisa estar presente nas escolas como condição para a ampliação de competências importantes para o desenvolvimento dos países. Considerada como condição essencial para a expressão pessoal e a convivência do pluralismo de ideias, contribuindo para "o reforço de valores como a diversidade, a tolerância, a transparência, a equidade e o diálogo” (UNIÃO EUROPEIA, 2009, p. L227/10).

Impulsionados pela UNESCO e pela União Europeia, diversos estudos têm sido desenvolvidos no âmbito das competências midiáticas como forma de enfrentamento das questões geradas pela inserção da mídia na sociedade e das transformações daí advindas. De acordo com as recomendações da União Europeia, a competência se refere à capacidade de mobilizar "o conhecimento, as aptidões e as capacidades pessoais, sociais e/ ou metodológicas, em situações profissionais ou em contextos de estudo e para efeitos de desenvolvimento profissional e/ou pessoal" com autonomia e responsabilidade (UNIÃO EUROPEIA, 2008, p. 111-114). A competência comunicativa se encontra, hoje, conectada com o ambiente midiático e é considerada um dos pilares da cidadania. Portanto, as competências midiáticas ligadas às competências comunicacionais e digitais (UNIÃO EUROPEIA, 2018) necessitam estar alinhadas às capacidades e habilidades compatíveis com atitudes e valores éticos. Nessa linha, Delgado-Ponce e Pérez-Rodrigues (2018, p. 1415), definem a competência midiática como:

[...] um conjunto interrelacionado e complexo de conhecimentos, destrezas e atitudes que nos permitem desenvolver-nos eficazmente na paisagem midiática, tanto para aceder, analisar e avaliar as mensagens como parte importante da nossa cultura contemporânea, como um componente midiático [...] gestionado por tecnologias digitais em constante evolução.

Dessa forma, a competência midiática está relacionada com uma leitura lúcida do tempo presente, com a garantia da liberdade de expressão responsável, a produção e a fruição de informação crítica, engajada e cidadã (DELGADO-PONCE; PÉREZRODRIGUES, 2018).

Ferrés (2007) e Ferrés e Piscitelli (2012) elaboram o conceito de competência midiática a partir de uma proposta metodológica para estudar os âmbitos da análise crítica e da produção criativa de conteúdos midiáticos. Este é definido por meio das seguintes dimensões: Tecnologia, Linguagem, Processos de Interação, Produção e Processos de Difusão, Ideologia e Valores e Estética. Estas dimensões são interdependentes e entendidas tanto nos modos de interpretação quanto de expressão do público em relação aos conteúdos midiáticos. A seguir, apresentamos de modo resumido a abrangência de cada uma delas: 
Quadro 1 - Competência midiática

\begin{tabular}{|c|c|}
\hline Dimensão & Descrição \\
\hline Tecnologia & $\begin{array}{l}\text { Capacidade para utilizar das Mídias/TIC com eficácia, adequar a } \\
\text { tecnologia aos fins previamente estabelecidos pelo usuário; conhecer } \\
\text { e integrar as inovações tecnológicas, bem como elaborar e manipular } \\
\text { imagens, sons etc. }\end{array}$ \\
\hline Linguagem & $\begin{array}{l}\text { Capacidade de interpretar adequadamente os códigos de uma } \\
\text { mensagem; avaliar o significado dos conteúdos e diferentes sistemas } \\
\text { de representação; expressar-se segundo códigos e sistemas de } \\
\text { representação distintos, dependendo do contexto e da mensagem } \\
\text { produzida ou transmitida. }\end{array}$ \\
\hline $\begin{array}{l}\text { Processos de } \\
\text { Interação }\end{array}$ & $\begin{array}{l}\text { Capacidade para avaliar os próprios hábitos midiáticos; reconhecer e } \\
\text { apreciar as emoções e valores nas mensagens assim como a habilidade } \\
\text { para interpretar os conteúdos dos meios criticamente, interatuar de } \\
\text { modo colaborativo nas plataformas facilitadas pelas redes sociais. }\end{array}$ \\
\hline $\begin{array}{l}\text { Produção e processos } \\
\text { de difusão }\end{array}$ & $\begin{array}{l}\text { Conhecer sobre os procedimentos de produção, programação e difusão } \\
\text { de conteúdos midiáticos; diferenciar entre as produções individuais } \\
\text { e as coletivas; entre as populares e as corporativas, etc.; conhecer e } \\
\text { utilizar sistemas de produção, programação e difusão de conteúdo, } \\
\text { colaborar na elaboração de produtos multimídia ou multimodais. } \\
\text { Conhecer os direitos de autoria e a produção responsável de conteúdo, } \\
\text { respeitando os direitos de propriedade intelectual. }\end{array}$ \\
\hline Ideologia e valores & $\begin{array}{l}\text { Conhecer a legislação que protege aos usuários e consumidores } \\
\text { de mídias, produzir e interpretar de modo cidadão, democrático e } \\
\text { autônomo as mensagens dos meios, detectando as intenções, os direitos } \\
\text { e os interesses que subjazem a seus conteúdos; habilidade para usar as } \\
\text { TIC de modo responsável e democrático, favorecendo a promoção do } \\
\text { entorno social. }\end{array}$ \\
\hline Estética & $\begin{array}{l}\text { Versa sobre a sensibilidade e atenção frente aos aspectos formais, dos } \\
\text { produtos midiáticos, desde uma perspectiva criativa e regida pelo bom } \\
\text { gosto; capacidade para usar e interpretar os meios seguindo padrões de } \\
\text { qualidade estética, de um modo criativo e original. }\end{array}$ \\
\hline
\end{tabular}

Fonte: elaborado pelos autores com base em Ferrés e Piscitelli (2012).

\section{Metodologia da Pesquisa}

A metodologia empregada partiu de uma abordagem quali-quantitativa. Devido à natureza das ciências sociais, as abordagens de pesquisa adotadas nessa área têm sido eminentemente qualitativas, visando a compreensão dos processos de significação, colocando em relevo a perspectiva dos participantes (SCHNEIDER; FUJII; CORAZZA, 2017). No 
entanto, os dados numéricos e quantificáveis também contribuem significativamente para a compreensão dos fenômenos sociais. Desse modo, a articulação de dados quantitativos e qualitativos auxilia o entendimento das situações de pesquisa, alertando para a necessidade de "esforço de reflexão do pesquisador para dar sentido ao material levantado e analisado" (GATTI, 2004, p. 13).

Quanto aos objetivos, a pesquisa é exploratório-descritiva com dados coletados por meio de questionários (HERNÁNDEZ SAMPIERI; FERNÁNDEZ-COLLADO; BAPTISTA-LUCIO, 2013, GIL, 2008) que visou a aproximação de uma temática pouco estudada no Brasil: os níveis de competência midiática em cada uma das suas dimensões.

A pesquisa foi constituída de diferentes etapas articuladas e complementares. A etapa inicial teve como objetivo a formação das equipes em cada uma das universidades. Os estudos englobaram textos sobre literacia midiática e competências midiáticas, bem como pesquisas empreendidas na Espanha sobre essa temática. A segunda etapa abrangeu a elaboração dos instrumentos de coleta de dados (questionários) para os diferentes segmentos da pesquisa, a qual foi bastante morosa porque levou em conta as especificidades interculturais que consideravam as línguas portuguesa e espanhola. A terceira etapa consistiu na aplicação dos questionários e validação dos dados, feita posteriormente pela Universidade de Huelva. A quarta etapa constituiu a elaboração de ações de formação a partir da análise dos resultados.

Para a aplicação dos questionários foram contatadas escolas de cada região e realizados os procedimentos relativos ao consentimento livre e esclarecido dos estudantes e seus responsáveis. Os alunos tiveram acesso ao questionário por meio de aplicativo online elaborado pela equipe espanhola. As escolas, em sua maioria, disponibilizaram os laboratórios de informática para a realização da pesquisa. Na etapa seguinte, os dados foram tratados estatisticamente e feita a validação dos resultados. Num primeiro momento, foram analisados os dados referentes a cada dimensão e organizados em relação aos níveis de competência midiática, distribuídos por meio de valores correspondentes às seguintes categorias: básico, básico/intermediário e avançado. Também cruzamos os dados de acordo com o sexo, idade, tipo de escola e formação com o fim de verificar as variações ocorridas a partir dessas categorias.

Dado o protocolo internacional a que a pesquisa estava articulada, procuramos contemplar devidamente as diversidades socioculturais e as singularidades dos diferentes campos empíricos deste estudo. Tal aspecto foi levado em conta na análise de dados, mas ainda assim, reconhecemos a dificuldade e a complexidade que este tipo de pesquisa suscita no âmbito de certas questões do questionário.

Composto de 24 questões, o questionário abrangeu as categorias: perfil dos participantes (7) e as dimensões das competências midiáticas: Tecnologia (3), Linguagem (3), Processo de Interação (3), Processos de Produção e Difusão (2), Ideologia e Valores (3), Estética (3). As perguntas eram de múltipla escolha, podendo ter respostas únicas ou possibilitar mais de uma escolha. As questões foram organizadas em uma planilha e posteriormente sistematizadas conforme o quadro a seguir: 
Quadro 2 - Distribuição das questões por categoria

\begin{tabular}{l|l}
\hline Categoria & Perguntas \\
\hline Perfil & P1, P2, P3, P3.1, P4, P4.1, P5 \\
\hline Dimensão Tecnologia & P14, P15, P22 \\
\hline Dimensão Linguagem & P8, P11, P12 \\
\hline Dimensão Processos de Interação & P13, P17, P20 \\
\hline Dimensão Processos de Produção e Difusão & $\mathrm{P} 19, \mathrm{P} 23$ \\
\hline Dimensão Ideologia e Valores & $\mathrm{P} 7, \mathrm{P} 16, \mathrm{P} 18$ \\
\hline Dimensão Estética & $\mathrm{P} 6, \mathrm{P} 9, \mathrm{P} 10$ \\
\hline
\end{tabular}

Fonte: elaborado pelos autores.

A aplicação foi feita em 2016, com a participação de estudantes de treze escolas do Ensino Fundamental das seguintes regiões: três escolas do Distrito Federal, duas de Minas Gerais, duas do Paraná, duas de Santa Catarina e quatro de São Paulo, selecionadas entre escolas privadas, públicas e privadas com incentivo público, totalizando 510 questionários respondidos, destes, 502 foram considerados válidos conforme quadro a seguir:

Quadro 3 - Distribuição de alunos por regiões:

\begin{tabular}{l|l} 
Região & Participantes \\
\hline Distrito Federal & 121 \\
\hline Minas Gerais & 104 \\
\hline Paraná & 101 \\
\hline Santa Catarina & 124 \\
\hline São Paulo & 52 \\
\hline Total & 502
\end{tabular}

Fonte: elaborado pelos autores.

Para a organização dos dados ${ }^{3}$, com o intuito de obter informações consistentes, foi feita uma padronização de variáveis pelo nome mais frequente, essa ação foi necessária, pois os participantes inseriam diferentes formas para o mesmo nome de escola ou estado, como, por exemplo MG, MINAS GERAIS e Minas, para Minas Gerais e assim por diante. Após depuração da base de dados, foi utilizado o software estatístico R (https://www.rproject.org/) de livre distribuição e código aberto para a geração dos primeiros resultados. Na sequência, foi utilizado o software SPSS versão 22 para um refinamento dos dados que possibilitou a leitura dos níveis de competência bem como o cruzamento desses níveis conforme as variáveis de perfil dos participantes.

3 Os dados foram tratados com o auxílio dos estatísticos: Daniel Gustavo Moreira (Tratamento inicial) e José Ricardo Favoretto (Tratamento pormenorizado) e do bolsista de iniciação científica Vinicius Guida. 


\section{Análise dos resultados}

A partir dos resultados encontrados, neste artigo apresentamos o perfil dos participantes e a análise dos níveis de competência midiática em cada uma das seis dimensões. Posteriormente, cruzamos a análise com os dados relativos ao perfil das crianças, tais como faixa etária, sexo, tipo de escola e formação em comunicação audiovisual.

\section{Perfil dos participantes}

As crianças e adolescentes que participaram da pesquisa estudavam em escolas públicas, privadas, e privadas com auxílio público, localizadas em contextos rural, urbano, centro e periferias das diferentes cidades, sendo que a escolha das escolas foi motivada pelos projetos de parceria que cada equipe já desenvolvia em suas universidades. Nesse sentido, o perfil familiar e financeiro dos/as estudantes era muito diversificado e dizia respeito a pequenos proprietários rurais, prestadores de serviços, profissionais liberais, operários, comerciários, funcionários públicos, empresários (SILVA; CARNEIRO; MEYER, 2019, p. 38).

Em relação ao local de origem dos participantes, o questionário foi aplicado no Distrito Federal (24,15\%); Santa Catarina (24,55\%); Minas Gerais (20,76\%): Paraná (20,16\%) e São Paulo (10,38\%). Houve um número maior de participantes do sexo masculino (55,29\%), em relação aos do sexo feminino (44,71\%). Em relação às faixas etárias, 15,97\% dos estudantes se encontravam com 9 anos; 27,74\% era composto por crianças de 10 anos; 30,14\% dos participantes tinham 11 anos e 26,15\% declarou ter 12 .

Gráfico 1 - Idade dos Participantes

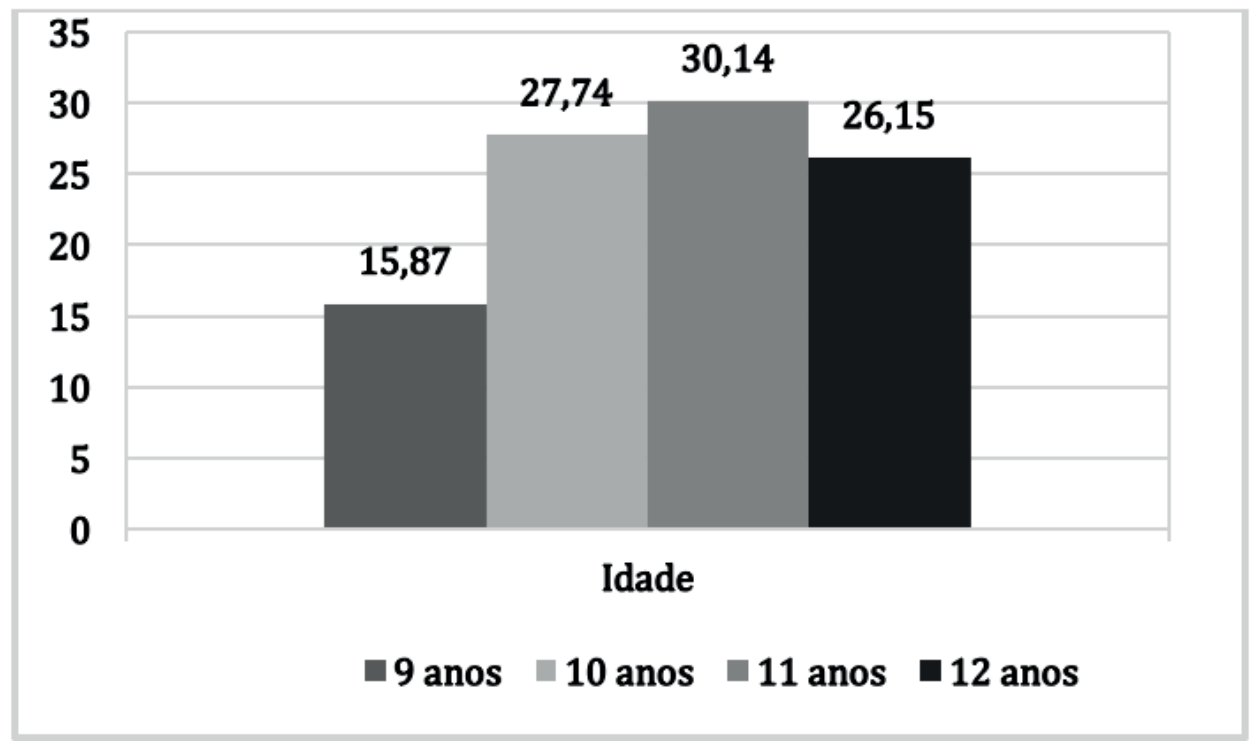

Fonte: elaborado pelos autores. 
Em relação à formação em comunicação audiovisual e digital (para entender, usar e produzir conteúdos audiovisuais, tais como filmes, vídeos etc.), os estudantes assinalaram: Nunca tive formação (27,74\%); Aprendi sozinho (28,94\%); Aprendi na escola (15,57\%); Aprendi com a minha família (20,56\%); Aprendi com os meus amigos (7,79\%); Aprendi em atividades extraescolares (1,40\%), conforme pode ser observado no Gráfico 2.

Gráfico 2 - Formação em Comunicação Audiovisual

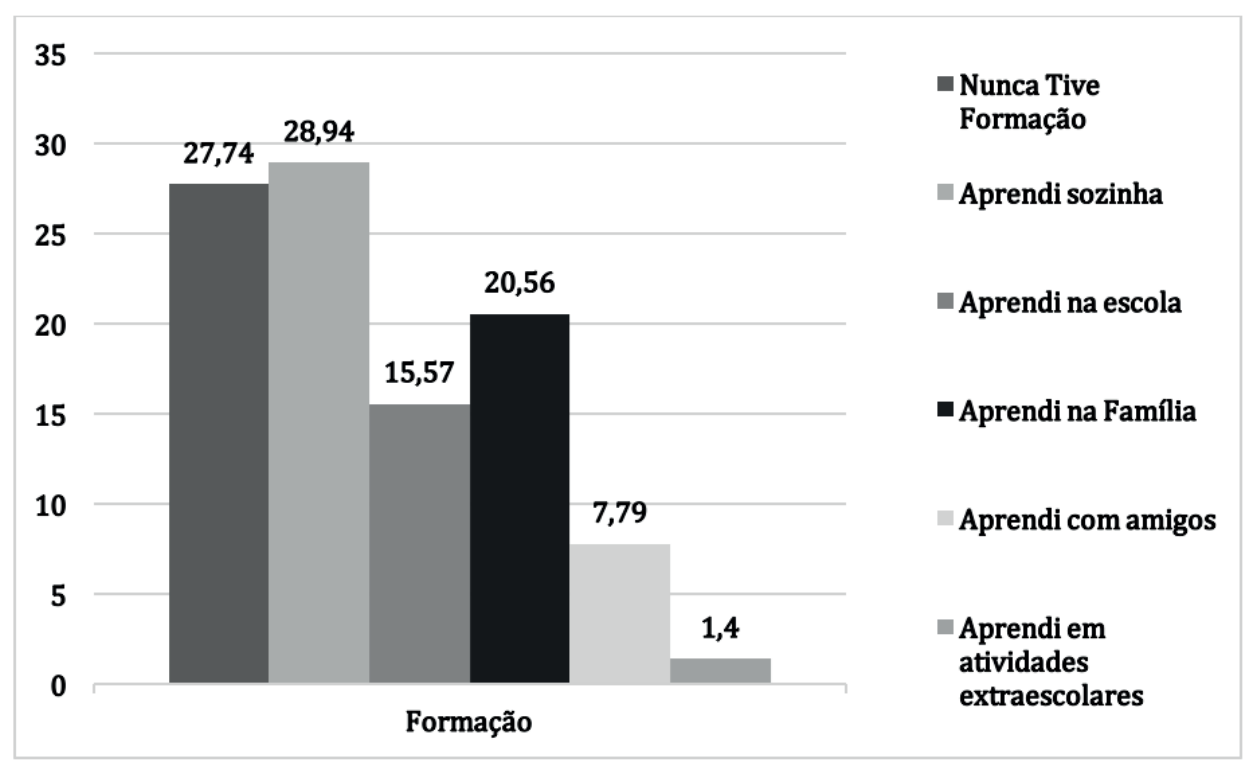

Fonte: elaborado pelos autores.

O Gráfico 2 mostra que, para essas crianças, a instituição de ensino teve pouco protagonismo em relação ao aprendizado com as mídias, indicando que há um espaço que pode ser ocupado pela escola na ampliação das competências midiáticas desse segmento. Esse dado é muito importante também para justificar a necessidade de políticas públicas de formação docente no âmbito da cultura digital.

Há ainda outros dados sobre a diversidade de consumos e práticas midiáticas de crianças e adolescentes que participaram da pesquisa e que atravessam as diferentes dimensões das competências. Vale fazer um breve destaque sobre os usos da internet, já que a maioria das crianças assinala nunca ter tido formação e ter aprendido sozinha.

As atividades mais frequentes mencionadas pelos/as estudantes foram: ver vídeos (95,01\%), jogar (91,42\%), ver filmes e séries da TV (83,03\%), procurar informação (82,83\%), ouvir música (82,63\%). Menos da metade mencionam: publicar vídeos no YouTube ou outros (47,31\%), usar e-mail $(43,51 \%)$ e ler notícias $(41,92 \%)$, como destacam Silva, Carneiro e Meyer (2019, p. 45). Tais dados dialogam com pesquisa do CETIC/CGI (NÚCLEO DE 
INFORMAÇÃO E COORDENAÇÃO DO PONTO BR, 2018a) and TIC Kids Online Brasil 2017 (NÚCLEO DE INFORMAÇÃO E COORDENAÇÃO DO PONTO BR, 2018b), ao destacar que $85 \%$ de crianças e adolescentes entre 9 e 17 anos eram usuários da internet e que o consumo de notícias on-line entre eles era de 51\%.

Embora tais dados demonstrem uma dimensão de inclusão digital, a pesquisa CETIC/ CGI (NÚCLEO DE INFORMAÇÃO E COORDENAÇÃO DO PONTO BR, 2018a) também destaca certa disparidade regional e socioeconômica em relação ao acesso e uso da rede: nas áreas urbanas (90\%) e rural (63\%); nas regiões Sudeste (93\%) e Norte (68\%); classe A (92\%), B (91\%), C (76\%) de acesso, diminuindo para 48\% nas classe DE, com tendência de acesso somente pelo celular wifi. Nesse quadro, é bom lembrar que, se na primeira década do século XXI, o mapa da exclusão/inclusão digital no Brasil sinalizava que apenas 33\% dos domicílios estavam conectados à rede (NERI, 2012), pesquisa do IBGE (2018) que aponta que ainda há cerca de 25\% da população brasileira sem conexão à internet.

\section{Os níveis de competência midiática em relação às dimensões}

Nessa etapa da pesquisa, a intenção foi de determinar os níveis de competência midiática obtidos pelos estudantes em cada dimensão, lembrando que não se trata de uma classificação fixa, mas de estabelecer parâmetros para a proposição de ações educativas que promovam o avanço em cada uma das dimensões da competência midiática. Nesse sentido foram identificados os níveis gerais de cada dimensão em termos de 'Básico' (nível 1), que corresponde aos conhecimentos, atuação e aptidões mais rudimentares, 'Básico/ Intermediário' (nível 2 e 3), que corresponde a ter conhecimentos, atuação e aptidões iniciais pouco consolidados, e ‘Avançado' (nível 4) que corresponde a conhecimentos, atuação e aptidões um pouco mais consolidados e autônomos na interação com a mídia. Cada pergunta foi categorizada a partir destes níveis e os resultados agrupados em cada uma das dimensões conforme indicado no Quadro 2. Esses dados foram posteriormente cruzados com elementos do perfil dos estudantes, tais como Sexo, Idade, Tipo de Escola e Formação para lidar com a mídia, e confrontados com o nível avançado a fim de auxiliar na compreensão sobre como se comportavam em cada categoria. Esse nível foi escolhido por representar o grau mais alto de competência midiática alcançado pelas crianças no questionário.

\section{Dimensão Tecnologia}

No tocante à dimensão Tecnologia, foram feitas questões relativas ao conhecimento de dispositivos, usos da internet e reconhecimento de interferência de programas na manipulação de imagens. Nesta dimensão, os valores relativos ao nível baixo de competência foram nulos, de forma que a maioria (75,1\%) alcançou o nível avançado, como se pode observar no Gráfico 3. 
Gráfico 3 - Níveis de Competência Midiática na Dimensão Tecnologia

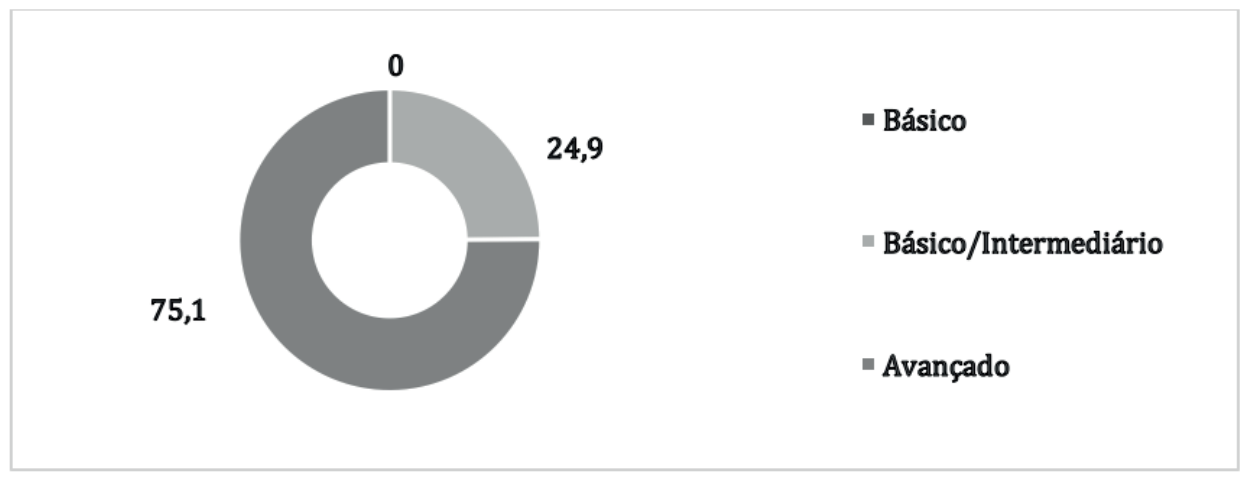

Fonte: elaborado pelos autores.

Essa foi a dimensão com maior potencial desenvolvido no nível avançado, quando relacionada com a categoria sexo, os percentuais se mantiveram equilibrados: $74,6 \%$ neste nível para as meninas e $75,5 \%$ para os meninos. Esse resultado mostra que a questão de gênero não interfere na apreensão desta dimensão.

Em relação à idade foi possível perceber um crescimento gradativo do nível avançado conforme a idade: 9 anos (66,3\%), 10 anos (73,4\%), 11 anos (76,8\%) e 12 anos (80,3\%), indicando que a experiência acumulada auxilia na apreensão desta dimensão, propiciando também uma maior autonomia de uso. Já em relação ao tipo de escola frequentada, a maior porcentagem foi registrada na escola privada (81,7\%), seguida da escola privada com apoio público (76,1\%) e da escola pública (74\%).

É sabido que as escolas públicas brasileiras de ensino básico oferecem menos possibilidade de acesso aos computadores, tablets e aplicativos diversificados do que as escolas privadas, isso leva a indagar se o tipo de acesso, bem como a sua frequência são condições importantes para a ampliação dos níveis de competência nessa dimensão. Finalmente, em relação à formação, as categorias mais significativas foram aprendi sozinho $(84,1 \%)$ e nunca tive formação (84,1\%), seguidos de aprendi em atividades extraescolares (71,4\%), aprendi com amigos (70\%), aprendi com a família (68,9\%) e aprendi na escola (65,4\%). Os dados reforçam a ideia de que essa dimensão se relaciona com a experiência, tem maior potencial de apreensão intuitiva e também revela aspectos da dimensão colaborativa de certas práticas e aprendizagens nesse âmbito.

\section{Dimensão Linguagem}

Com relação à dimensão Linguagem, as questões se referiam ao reconhecimento do papel dos elementos da linguagem audiovisual na composição dos significados da mensagem 
midiática. Esta dimensão também apresentou um percentual significativo de crianças no nível avançado (50,6\%), sendo que a variável sexo indicou um avanço maior na categoria feminino (57,1\%) do que na categoria masculino (45,3\%).

Gráfico 4 - Níveis de Competência Midiática na Dimensão Linguagem

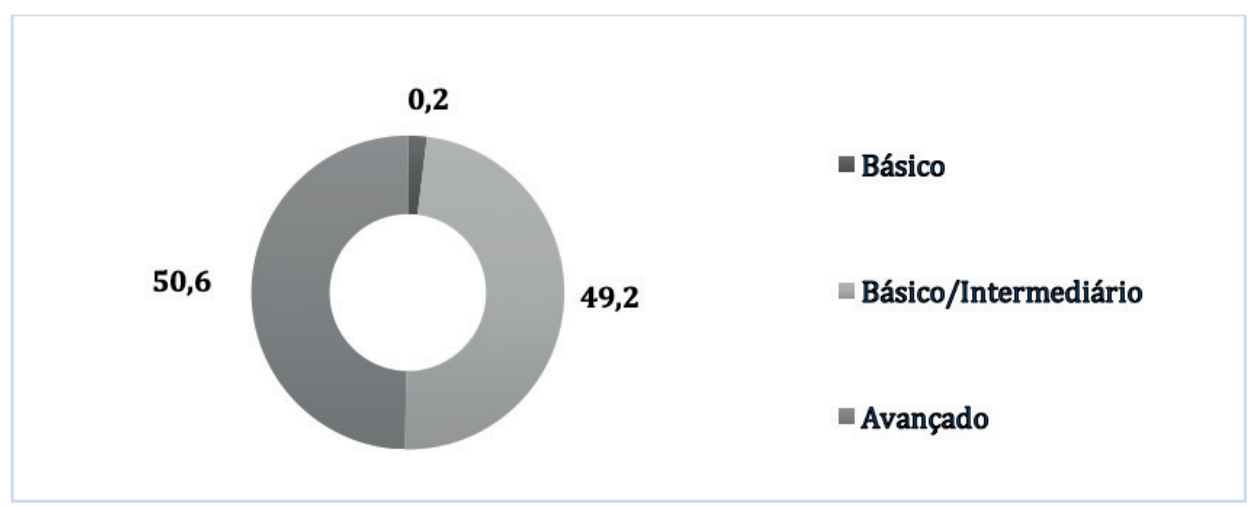

Fonte: elaborado pelos autores.

A progressão por faixa etária se manteve nesta dimensão: 9 anos (43,8\%), 10 anos (45,3\%), 11 anos (52,3\%) e 12 anos (58,3\%). Em relação ao tipo de escola, também se confirmou a prevalência da escola privada (56,7\%), sendo seguida agora pela escola pública (50,3\%) e escola privada com apoio público (45,7\%), indicando que para essa dimensão o acesso aos diferentes dispositivos é importante, mas não determinante, cabendo investigar mais essa relação.

Na categoria formação os dados registrados para o nível avançado foram aprendi com a família (58,3\%), aprendi sozinho (50,3\%) e nunca tive formação (49,6\%), seguidos de aprendi com amigos (46,7\%), aprendi na escola (46,2\%) aprendi em atividades extraescolares (28,6\%). Os resultados obtidos nessa categoria levam a indagar se esta dimensão estaria mais relacionada às trocas sociais que ao contato direto com a mídia.

\section{Dimensão Processos de Interação}

A dimensão Processos de Interação apresentou questões relacionadas à audiência e à conduta dos participantes nas redes sociais. Essa dimensão teve o menor percentual de crianças que alcançaram o nível avançado (10,36\%) conforme pode ser observado no gráfico 5. Em relação à categoria Sexo, o percentual do nível avançado nos meninos $(11,9 \%)$ apresentou um ligeiro aumento em comparação com as meninas (8,5\%), indicando que é necessário realizar outros estudos para verificar se esta diferença se mantém. 
Gráfico 5 - Níveis de Competência Midiática na Dimensão Processos de Interação

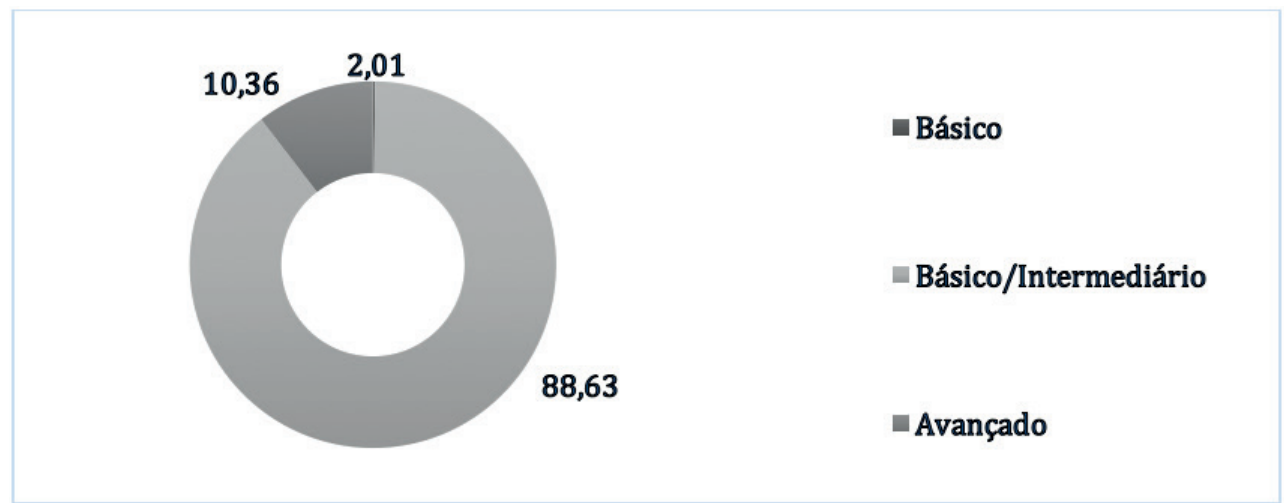

Fonte: elaborado pelos autores.

Quanto à idade, foram registrados os seguintes valores no nível avançado: 9 anos (7,5\%), 10 anos (7,2\%), 11 anos (12,6\%) e 12 anos (12,9\%), indicando que a idade é relevante em termos de aquisição dessa dimensão e mostrando que a partir dos 11 anos cresce a interação das crianças nas redes. Em relação ao tipo de escola, houve uma prevalência do nível avançado na escola pública (11,1\%) e privada com incentivo público (10,9 \%) em relação à escola privada (5,0\%), embora sejam percentuais pequenos comparados ao todo da dimensão. O percentual da escola privada é praticamente a metade dos outros, o que indica a necessidade de um aprofundamento para compreender o porquê dessa diferença.

Na categoria formação os dados registrados para o nível avançado foram aprendi sozinho (15,9\%), aprendi com a família (9,7\%), e nunca tive formação (8,4\%), seguidos de aprendi com amigos (6,7\%), aprendi na escola (5,1\%) aprendi em atividades extraescolares $(0,0, \%)$. Os resultados obtidos nessa categoria levam à necessidade de um aprofundamento da pesquisa para compreender melhor a influência dos fatores analisados sobre a aquisição de um nível mais avançado nessa dimensão. Porém, os dados mostram que menos de 50\% das crianças publicam vídeos no Youtube, usam o e-mail ou leem notícias on-line.

\section{Dimensão Processos de Produção e Difusão}

As questões referentes a esta dimensão trataram das medidas de segurança na internet e dos conhecimentos relativos às funções dos profissionais que atuam na área de audiovisual, bem como as etapas de realização de uma produção midiática.

Essa dimensão obteve o percentual de 26,9\% no nível avançado. Em relação à categoria sexo, apresentou um ligeiro aumento no percentual do nível avançado nas meninas (29,5\%) em comparação com os meninos (24,8\%), indicando que as meninas são um pouco mais ativas em relação à produção e difusão. 
Gráfico 6 - Níveis de Competência Midiática na Dimensão Processos de Produção e Difusão

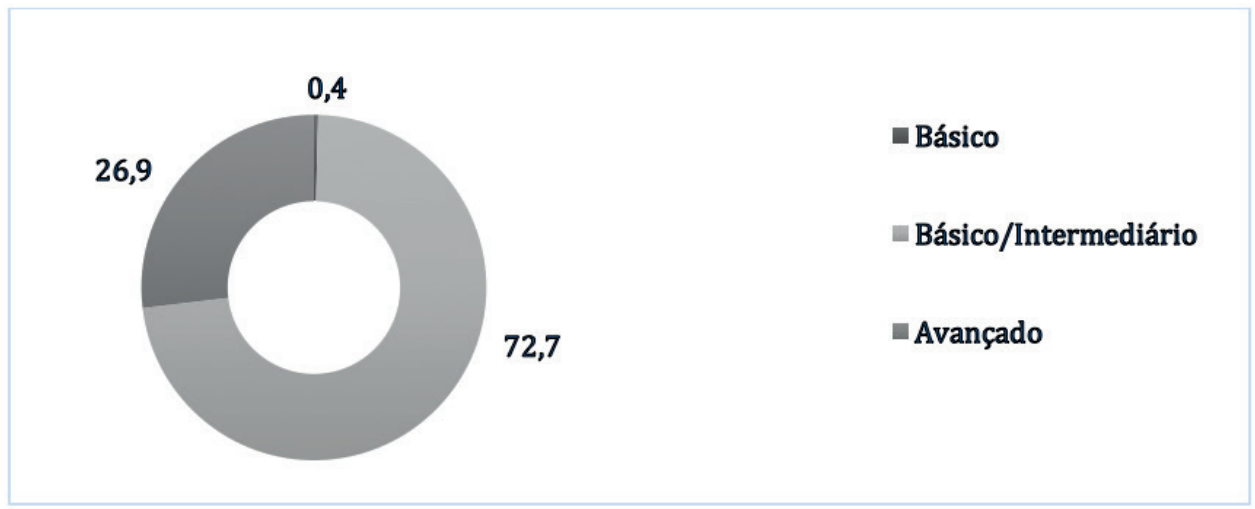

Fonte: elaborado pelos autores.

Quanto à idade, foram registrados os valores: 9 anos (15\%), 10 anos (23,3\%), 11 anos (29,1\%) e 12 anos (36,4\%), indicando que o fator idade é relevante em termos de aquisição dessa dimensão. Com relação ao tipo de escola, foram registrados os seguintes percentuais no nível avançado: escola privada (40,0\%), na escola pública (26,5\%) e privada com incentivo público (13\%), sendo notório o desempenho mais elevado em alunos de escola privada, que representam quase o dobro da escola pública.

Em relação à formação, os dados obtidos para o nível avançado foram aprendi sozinho (37,9\%), aprendi em atividades extraclasse (28,6\%), aprendi com amigos (26,7\%), aprendi com a família (25,2\%) e nunca tive formação (22,3\%), seguidos por aprendi na escola (16,7\%). Aqui chama a atenção que a aprendizagem na escola teve o menor escore de avanço e nos aponta pistas para indagar quais são os incentivos dados para o desenvolvimento dessa dimensão no ambiente escolar. E ainda, como os conhecimentos formais, não formais e informais estão sendo articulados nas propostas curriculares.

\section{Dimensão Ideologia e Valores}

A dimensão Ideologia e Valores apresentou questões relacionadas à identificação das intenções de peças publicitárias, aos critérios de escolha na internet e às iniciativas de ações que valorizam a cidadania no ambiente virtual.

Esta dimensão obteve o segundo menor percentual no nível avançado entre as dimensões pesquisadas (12,7\%). E foi a que teve o maior índice de nível básico (7,6\%), indicando a necessidade de ampliação das ações formativas nessa dimensão. 
Gráfico 7 - Níveis de Competência Midiática na Dimensão Ideologia e Valores

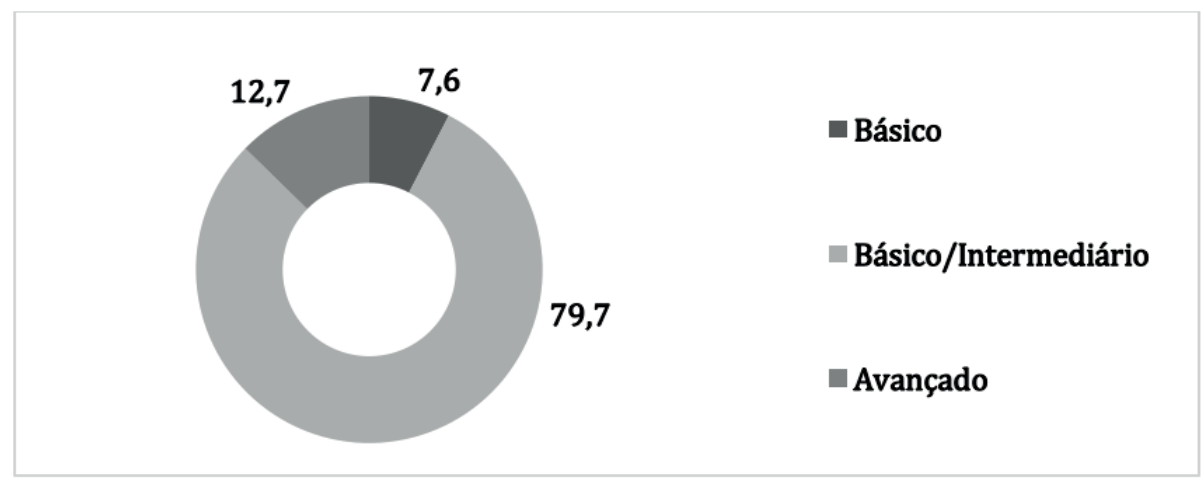

Fonte: elaborado pelos autores.

Quando se compara a categoria sexo, o nível avançado teve pouca variação entre feminino (12,5\%) e masculino (12,9\%). Já em relação à idade, foram obtidos os seguintes percentuais: 9 anos (15\%), 10 anos (10,1\%), 11 anos (15,9\%) e 12 anos (10,6\%), houve aqui uma variação inesperada que necessita de uma maior investigação para identificar suas causas. Quando se confronta o tipo de escola, o nível avançado teve maior percentual na categoria privada (20\%), seguida da pública (12,1\%) e privada com incentivo público (8,7\%), indicando que a escola privada ou a condição socioeconômica do aluno pode interferir na ampliação do nível de competência nessa dimensão.

Em relação à formação, os dados obtidos para o nível avançado foram: aprendi em atividades extraclasse (28,6\%), aprendi sozinho (20,7\%), aprendi na escola (12,8\%), aprendi com amigos (10\%), aprendi com a família (8,7\%), e nunca tive formação (7,2\%). Apesar da categoria aprendi sozinho abranger um percentual alto de respostas no nível avançado, esta parece ser melhor apreendida em contextos de interação social ou de conhecimento sistematizado.

\section{Dimensão Estética}

A dimensão Estética foi apresentada por meio de questões relacionadas ao reconhecimento de estratégias de estetização de produtos alimentícios em peças publicitárias. Esta dimensão apresentou o terceiro maior percentual no nível avançado (36,9\%), significando que, apesar de ser uma dimensão complexa, os estudantes demonstraram ter uma relativa intimidade com ela. 
Gráfico 8 - Níveis de Competência Midiática na Dimensão Estética

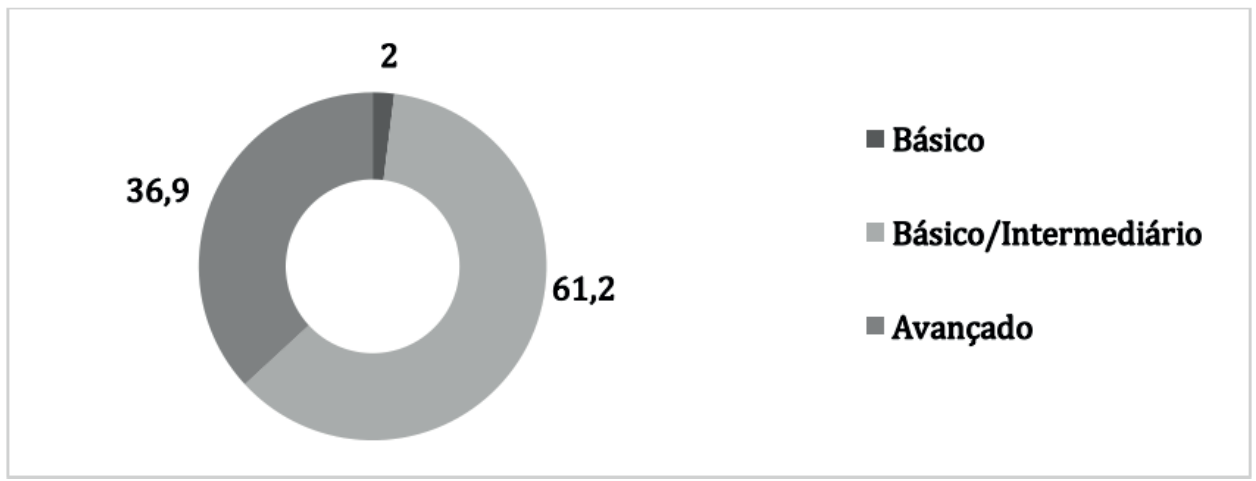

Fonte: elaborado pelos autores.

Quanto ao sexo, o feminino apresentou um percentual maior nessa dimensão (40,6\%) que o masculino (33,8\%). Em relação à idade, se manteve a progressão com o passar dos anos, obtendo assim o seguinte registro: 9 anos (32,5\%), 10 anos (33,1\%), 11 anos (36,4\%) e 12 anos (43,9\%). Considerando o tipo de escola, os resultados obtidos foram: escola pública (37,4\%), escola privada (36,7\%) e escola privada com incentivo público (32,6\%), indicando não haver uma prevalência significativa entre as categorias abrangidas.

Quanto à formação, os dados obtidos para o nível avançado foram: aprendi em atividades extraclasse (57,1\%), aprendi com amigos (43,3\%), aprendi sozinho (41,4\%), nunca tive formação (37,4\%) aprendi com a família (35\%) e aprendi na escola (25,6\%).

\section{Dimensões em relação aos perfis}

Comparando todas as dimensões com o perfil idade, é possível perceber que à exceção da categoria Ideologia e Valores, as outras demonstraram um crescimento do nível avançado com o aumento da idade, indicando que o conhecimento acumulado e a experiência auxiliam o desenvolvimento da competência midiática, como se constata no Gráfico 9. 
Gráfico 9 - Comparação entre as Dimensões e a Faixa Etária

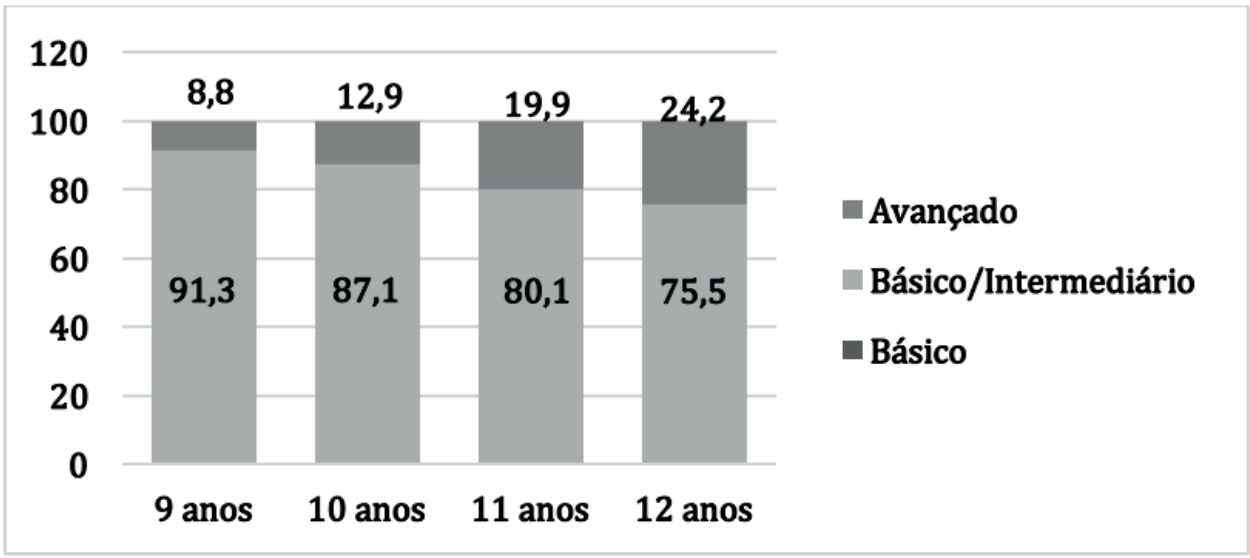

Fonte: elaborado pelos autores.

Com relação ao sexo, houve um predomínio das meninas em alcançar o nível avançado de competência, sendo que as dimensões Tecnologia (0,1\%) e Ideologia e Valores $(0,4 \%)$ apresentaram uma diferença percentual irrisória a favor dos meninos, indicando que as meninas apresentam um grande potencial de desenvolvimento frente às mídias.

Gráfico 10 - Comparação entre as Dimensões e o Sexo

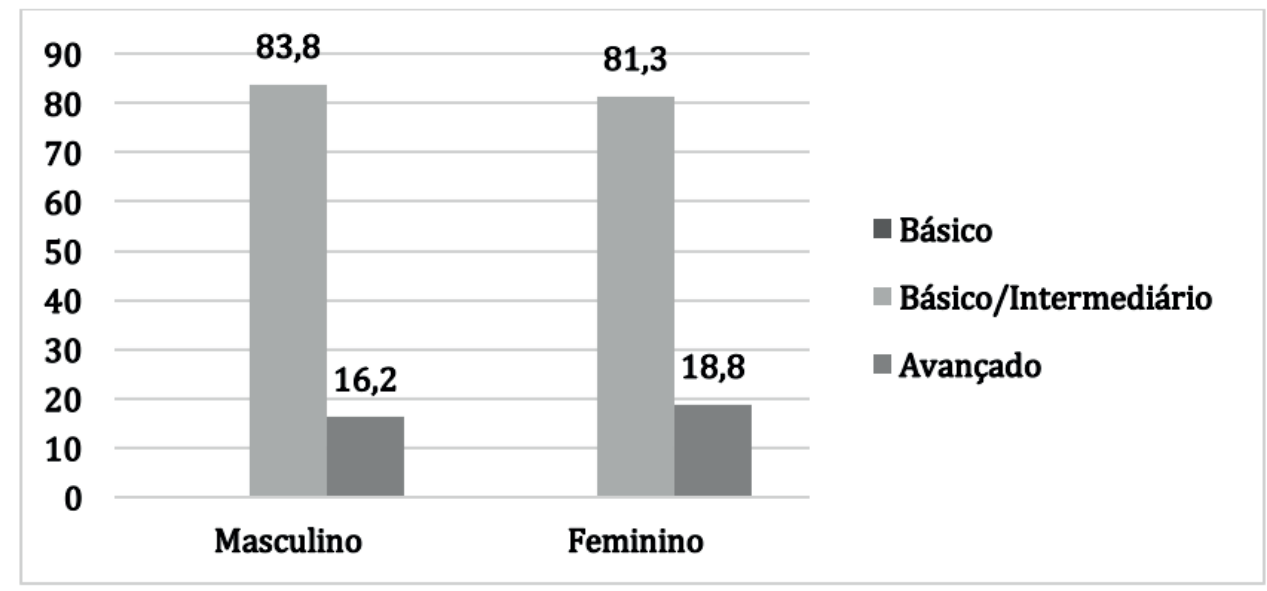

Fonte: elaborado pelos autores.

Em relação ao tipo de escola, houve uma prevalência da escola privada em relação aos outros tipos de escola. Uma maior diferença percentual em relação à escola pública foi significativa apenas nas dimensões Estética e Processos de Interação, o que indica a necessidade de investimento em políticas públicas nessa área. 
Gráfico 11 - Comparação entre as Dimensões e o Tipo de Escola

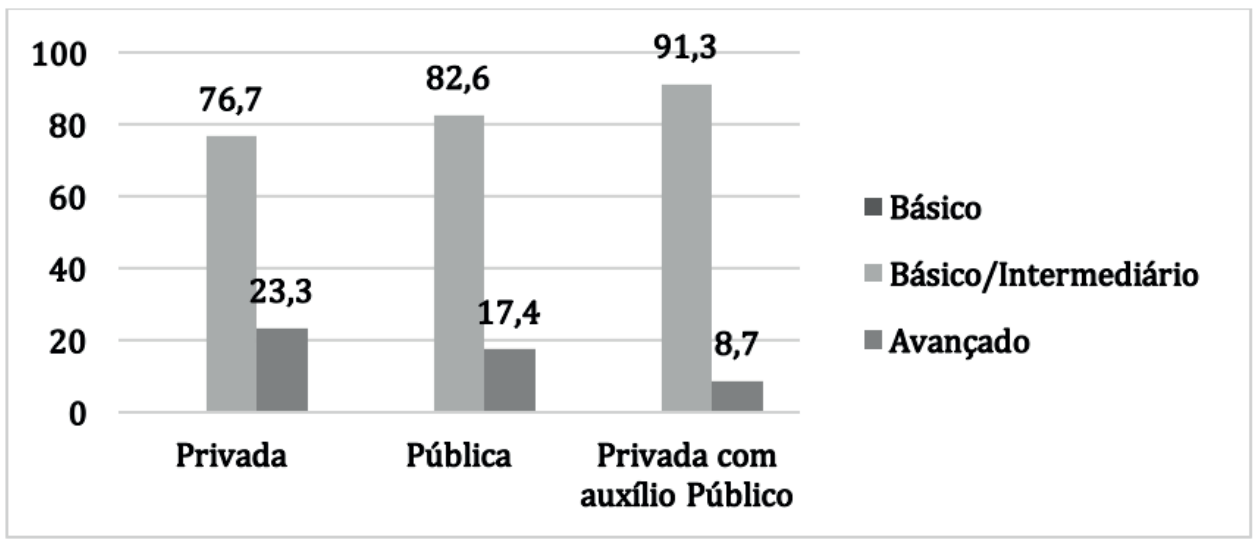

Fonte: elaborado pelos autores.

Com relação à formação em comunicação audiovisual e digital, houve uma grande alternância entre as categorias, com prevalência do aprender sozinho, seguido de aprendi em atividades extraclasse, vale salientar que a opção aprendi na escola está entre os escores mais baixos em todas as dimensões estudadas. Esse resultado indica que a escola necessita definir um plano de ações, que envolva os pais e os professores - e, também, aprimore suas competências - voltadas para auxiliar o desenvolvimento da competência midiática, principalmente aquelas que dizem respeito à compreensão da função social da mídia e a capacidade de análise e expressão crítica por meio da mídia.

Gráfico 12 - Comparação entre as Dimensões e a Formação

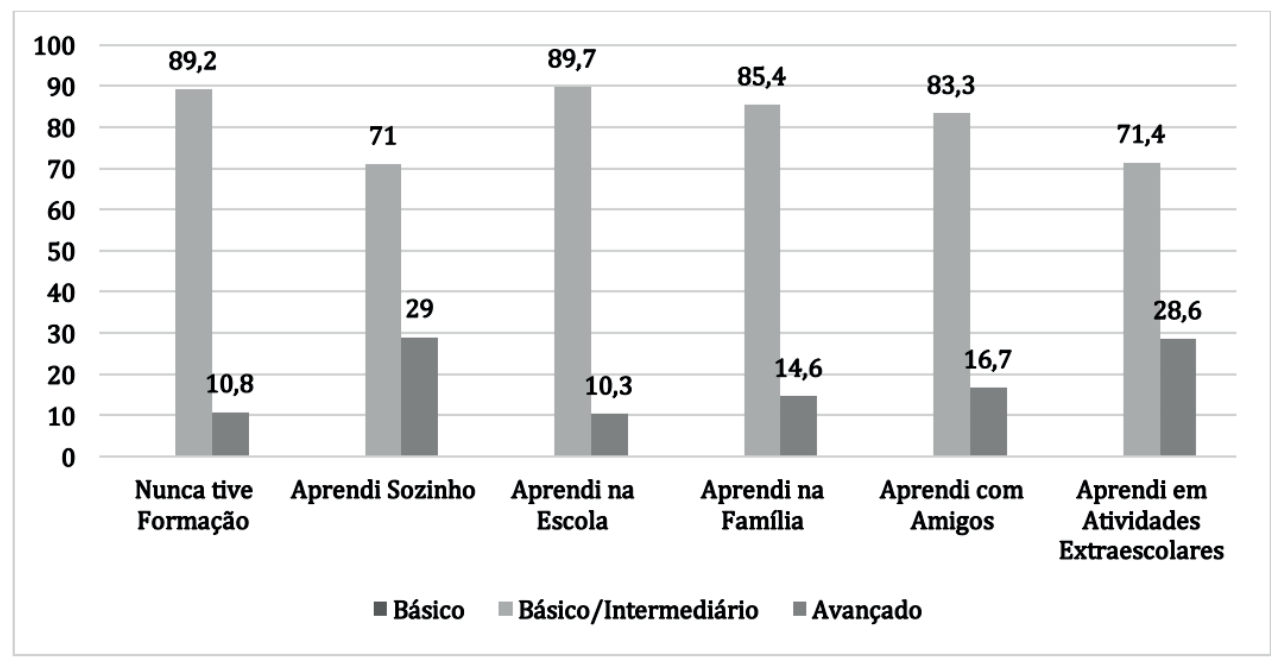

Fonte: elaborado pelos autores. 
Comparando os níveis avançados em todas as dimensões (Gráfico 13) podemos perceber que as dimensões que necessitam maior atenção são Processos de Interação e Ideologia e Valores, seguida de Processos de Produção e Difusão, justamente as dimensões mais ligadas às ações sociais, aos mecanismos de proteção e ao protagonismo.

Gráfico 13 - Comparação do Nível Avançado entre todas as Dimensões

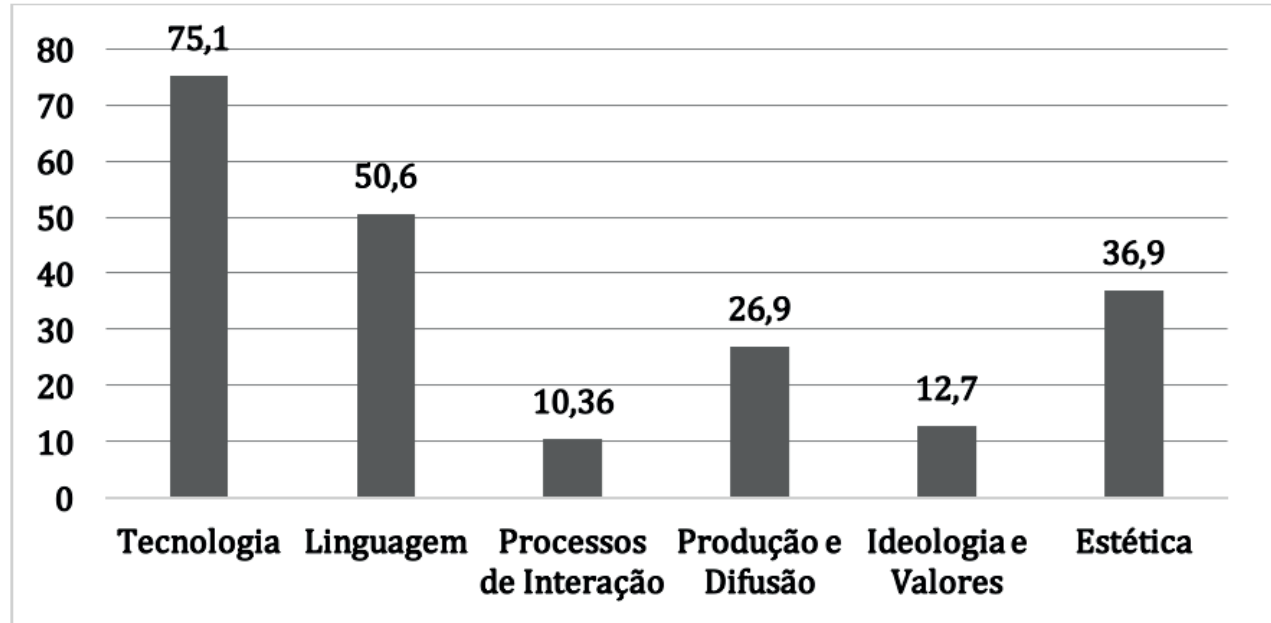

Fonte: elaborado pelos autores.

Os diferentes níveis de competência midiática vistos acima e suas formas de pertencimento na cultura digital reforçam a importância de considerar os diferentes modos de ser criança e adolescente diante das telas digitais. Também revelam o lugar de destaque dos diferentes artefatos digitais nos processos de socialização e das formas de participação no contemporâneo. Quanto às especificidades das práticas midiáticas, destacamos a necessidade e o desafio das mediações na perspectiva da mídia-educação (RIVOLTELLA, 2012, BELLONI, 2010, FANTIN; GIRARDELLO, 2009) para assegurar os direitos das crianças em relação às mídias relativos aos 3 P: Proteção, Provisão e Participação (PINTO; SARMENTO, 1997, BUCKINGHAM, 2007, PROUT, 2010), aqui entendidos em suas tensões, interdependências e contradições.

\section{Considerações Finais}

O presente artigo teve como objetivo apresentar os resultados referentes aos diferentes níveis de competência midiática de crianças de 9 a 12 anos. Estes foram sistematizados em duas etapas. Na primeira, apresentamos o perfil das crianças que participaram da pesquisa. Em seguida, enfatizamos os níveis obtidos por elas em cada uma das dimensões: Tecnologia, Linguagem, Processos de Interação, Processos de Produção e Difusão, Ideologia e Valores e Estética. Cruzando depois essas dimensões 
com elementos do perfil como 'Sexo', 'Idade', 'Tipo de Escola’ e 'Formação', analisamos como se comportavam em relação ao nível avançado, ou seja, ao nível em que a criança demonstra maior apreensão da dimensão pesquisada.

De uma maneira geral, as respostas obtidas se encontravam em um nível bastante inicial com os conhecimentos básicos ainda pouco consolidados (nível básico/intermediário), ou seja, apresentam noções básicas, mas ainda com pouca autonomia. Isso aponta a necessidade de ampliação de experiências que permitam a transição para o nível avançado, no qual a criança já apresenta conhecimentos mais consolidados e os mobiliza na interação com as mídias de maneira mais autônoma.

Chama a atenção que a dimensão Tecnologia seja a que apresenta maior percentual de crianças em nível avançado e que as dimensões Processos de Interação e Ideologia e Valores apresentem os percentuais mais baixos, pois indica que um avanço nos conhecimentos acerca da dimensão tecnologia não garante que esse uso seja ético, autônomo e responsável. Por outro lado, a aprendizagem na escola esteve entre os menores escores indicando a necessidade de desenvolvimento de ações de formação, como tem sido recomendado pelos órgãos internacionais como a UNESCO. No sentido de colmatar estas carências e como um dos objetivos deste projeto, as universidades federais de Santa Catarina e de Juiz de Fora (FANTIN; BORGES, 2019) desenvolveram ações de formação voltadas tanto para os professores quanto para as crianças, respectivamente.

Outro dado importante é o que diz respeito ao desempenho um pouco mais avançado de crianças oriundas de escolas privadas, indicando que pode haver um componente socioeconômico relacionado a esse resultado. Vale lembrar que a dimensão Processos de Interação obteve o menor escore para a escola privada. Justamente a dimensão que se refere à capacidade para refletir criticamente sobre a sua própria interação com a mídia, interpretar os conteúdos, interagindo de modo solidário e colaborativo, o que indica mais uma vez que o acesso por si só não garante a aquisição desta competência. Reforça assim a necessidade de políticas públicas que garantam acesso de qualidade às mídias e ações educativas que auxiliem o desenvolvimento da competência midiática das crianças nas escolas. Para que elas possam acessar, fruir, interpretar e produzir audiovisuais, como também possam reivindicar seu direito a uma mídia de qualidade. Isso é necessário tanto no que diz respeito ao currículo escolar quanto à formação permanente de professores para que estes possam ofertar às crianças oportunidades concretas de desenvolvimento de competências, especialmente às camadas mais pobres da população que são atendidas pelo ensino público. Além disso, os profissionais de mídia também podem atuar nessa área oferecendo produtos de qualidade, tendo em conta o seu papel social como formadores de opinião e promovendo o desenvolvimento da literacia midiática.

Nesse sentido, é importante destacar que a partir do mapeamento das competências midiáticas entre crianças e adolescentes e das reflexões construídas no contexto mais amplo da pesquisa, foi possível ir além da constatação e desenvolver diversas propostas formativas, voltadas para crianças, adolescentes, jovens estudantes e professores, com intenção de 
potencializar saberes e experiências diferenciadas de produção de audiovisuais, como se pode ver em Borges e Silva (2019).

Considerando o alcance circunscrito da pesquisa e seus limites e o desafio de contrastar tais dados com pesquisas realizadas em outros contextos, ainda assim emergiram dos resultados situações que indicam a necessidade de novas investigações e a urgente inclusão dos estudos sobre a mídia e a cultura digital nas escolas brasileiras.

\section{Referências}

BELLONI, M. L. Crianças e mídias no Brasil. Campinas: Papirus, 2010.

BORGES, G.; SILVA, M. B. (orgs). Competências midiáticas em cenários brasileiros: interfaces entre comunicação educação e artes. Juiz de Fora: Editora da UFJF, 2019. Disponível em: https://drive.google.com/ file/d/15gm5LyzgjX0xJ7fLolYfF2Av4eAdGA4B/view. Acesso em: 2 set. 2020.

BUCKINGHAM, D. Crescer na era das mídias eletrônicas. São Paulo: Edições Loyola, 2007.

BUCKINGHAM, D. The Media Education Manifesto. Polity Press: Cambridge. 2019.

DELGADO-PONCE, A.; PÉREZ-RODRIGUES, M. A. La competencia mediática. In: GARCIA-RUIZ, R.; PÉREZ-RODRIGUES, M. A.; TORRES, A. Educar para los nuevos medios. 2018, on-line, p. 13-27.

FANTIN, M.; BORGES, G. Competências midiáticas e a produção audiovisual entre jovens: experiências investigativas e formativas. In: BORGES, G.; SILVA, M. B. (orgs). Competências midiáticas em cenários brasileiros: interfaces entre comunicação educação e artes. Juiz de Fora: Editora da UFJF, 2019 , p. 57-72. Disponível em https://drive.google.com/file/d/15gm5LyzgjX0xJ7fLolYfF2Av4eAdGA4B/view. Acesso em: 2 set. 2020.

FANTIN, M.; GIRARDELLO, G. Diante do abismo digital: mídia-educação e mediações culturais. Perspectiva, v. 27 n. 1, p. 69-96, 2009. Disponível em: https://periodicos.ufsc.br/index.php/perspectiva/ article/view/2175-795X.2009v27n1p69/12291. Acesso em: 30 ago. 2020.

FERRÉS, J. La competencia en comunicación audiovisual. Comunicar, v. 15, n.29, p. 100-107, 2007. Disponível em: https://www.revistacomunicar.com/index.php?contenido=detalles\&numero=29\&articulo=29-2007-17. Acesso em: 15 jul. 2019.

FERRÉS, J.; PISCITELLI, A. La competencia mediática: propuesta articulada de dimensiones e indicadores. Comunicar, v. 19, n. 38, p. 75-82, 2012. Disponível em: www.redalyc.org/articulo.oa?id=15823083010. Acesso em: 15 jul. 2019.

FLORIDI, L. La quarta revoluzione: come l'infosfera sta transformando il mondo. Milano: Raffaello Cortina, 2017.

GATTI, B. A. Estudos quantitativos em educação. Educação e Pesquisa. v. 30, n. 1, p. 11-30, 2004. Disponível em: http://www.scielo.br/pdf/ep/v30n1/a02v30n1.pdf. Acesso em: 15 jul. 2020.

GIL, A. C. Como elaborar projetos de pesquisa. São Paulo: Atlas, 2008.

HERNÁNDEZ-SAMPIERI, R.; FERNÁNDEZ-COLLADO, C.; BAPTISTA-LUCIO, M. del P. Metodologia de La Investigación. México: Mc-GrawHill, 2013.

IBGE. PNAD Contínua TIC 2017: Internet chega a três em cada quatro domicílios do país. 2018. Disponível em: https://agenciadenoticias.ibge.gov.br/agencia-sala-de-imprensa/2013-agencia-de-noticias/ 


\section{MÁRCIA BARBOSA DA SILVA | GABRIELA BORGES | MÔNICA FANTIN | \\ MARIA ALZIRA ALMEIDA PIMENTA | IGNÁCIO AGUADED}

releases/23445-pnad-continua-tic-2017-internet-chega-a-tres-em-cada-quatro-domicilios-do-pais. Acesso em: 30 ago. 2020.

LIVINGSTONE, S. What is media literacy? Intermedia, v. 32, n. 3, p. 18-20, 2004. Disponível em: http:// eprints.lse.ac.uk/1027/. Acesso em: 15 jul. 2019.

MARTÍN-BARBERO, J. El cambio em la percepción de los jovenes. Sociabilidades, tecnicidades y subjetividades. In: MORDUCHOWCZ, R. (org). Los jovenes y las pantallas: nuevas formas de sociabilidade. Barcelona: Gedisa, 2008.

NERI, M. Mapa da inclusão digital. Rio de Janeiro: FCC, CPS, 2012.

NÚCLEO DE INFORMAÇÃO E COORDENAÇÃO DO PONTO BR (ed.). Pesquisa sobre o uso das tecnologias de informação e comunicação nos domicílios brasileiros: TIC domicílios 2018. São Paulo; Comitê Gestor da Internet no Brasil, 2018. Disponível em: https://cetic.br/pesquisa/kids-online/indicadores. Acesso em: 30 ago. 2020.

NÚCLEO DE INFORMAÇÃO E COORDENAÇÃO DO PONTO BR (ed). Pesquisa sobre o uso da internet por crianças e adolescentes no Brasil: TIC kids online Brasil 2017. São Paulo: Comitê Gestor da Internet no Brasil, 2018, online. Disponível em https://cetic.br/media/docs/publicacoes/2/tic_kids_online_2017_livro_ eletronico.pdf. Acesso em: 15 set. 2020.

PEREIRA, S.; PINTO, M.; MOURA, P. Niveis de literacia midiática: estudo exploratório com jovens do 12.ano. Braga: CECS/UMinho, 2015.

PINTO, M.; SARMENTO, M. J. As crianças: contextos e identidades. Centro de Estudos da Criança. Braga: Universidade do Minho, 1997.

PRETTO, N. Uma dobra no tempo: um memorial (quase) acadêmico. Ilhéus, BA: Editus, 2015.

PRETTO, N. Entrevista do mês de janeiro: Nelson Pretto. Observatório de Análise Política em Saúde (OAPS), 2019. Disponível em: https://www.analisepoliticaemsaude.org/oaps/noticias/ cf05431e066ad52fdf9e01536d011b63/. Acesso em: 2 set. 20.

PROUT, A. Participação, políticas e condições de infância em mudança. In: MULLER, F. (Org). Infância em perspectiva: políticas, pesquisas e instituições. São Paulo: Cortez, 2010 (p. 21-41)

ROMERO RODRÍGUEZ, L. M. et al. Analfanautas y la cuarta pantalla: ausencia de infodietas y de competencias mediáticas e informaciones en jóvenes universitários latinoamericanos. Fonseca. Journal of Communication, n. 12, p. 11-25, 2016. Disponível em: http://revistas.usal.es/index.php/2172-9077/article/ view/fjc2016121125/15076. Acesso em: 15 jul. 2019.

RIVOLTELLA, P. C. Retrospectivas e tendências da pesquisa em mídia-educação no contexto internacional. In: FANTIN, M.; RIVOLTELLA, P. C. (org.). Cultura digital e escola: pesquisa e formação de professores. Campinas: Papirus, 2012, p. 17-29.

SCHNEIDER, E. M.; FUJII, R. A. X.; CORAZZA, M. J. Pesquisas qualiquantitativas: contribuições para a pesquisa em ensino de ciências. Revista Pesquisa Qualitativa, v. 5, n. 9, p. 569-584, 2017. Disponível em: https://editora.sepq.org.br/index.php/rpq/article/view/157. Acesso em: 6 maio 2019.

SILVA, M. B.; CARNEIRO, V. L. Q.; MEYER, M. Crianças de 9 a 12 anos e sua relação com a mídia. In: BORGES, G.; SILVA, M. B. (orgs). Competencias midiáticas em cenários brasileiros: interfaces entre comunicação educação e artes. Juiz de Fora: Editora da UFJF, 2019, p. 36-56. Disponível em: https://drive. google.com/file/d/15gm5LyzgjX0xJ7fLolYfF2Av4eAdGA4B/view. Acesso em: 2 set. 2020. 
UNESCO. Grunwald Declaration. Unesco: Grunwald (Alemanha), online, 1982. Disponível em: http://www.unesco.org/education/pdf/MEDIA_E.PDF. Acesso em: 28 abr. 2019.

UNESCO. Paris Agenda or 12 recommendations for media education, online. Paris: Unesco, 2007. Disponível em: http://www.diplomatie.gouv.fr/fr/IMG/pdf/Parisagendafin_en.pdf. Acesso em: 30 abr. 2019.

UNIÃO EUROPEIA. Recomendação do Parlamento Europeu e do Conselho de 23 de Abril de 2008 relativa à instituição do Quadro Europeu de Qualificações para a aprendizagem ao longo da vida (2008/C 111/01). Jornal Oficial da União Europeia/PT, p. C 111/1 - C 111/7. Disponível em: https://wwwcdn.dges.gov.pt/ sites/default/files/recomendacao.pdf. Acesso em: 1 maio 2019.

UNIÃO EUROPEIA. Recomendação da Comissão de 20 de Agosto de 2009 sobre literacia mediática no ambiente digital para uma indústria audiovisual e de conteúdos mais competitiva e uma sociedade do conhecimento inclusiva (2009/625/CE). Jornal Oficial da União Europeia/PT, p.L 227/9 aL 227/12, Disponível em: https://eur-lex.europa.eu/legal-content/PT/TXT/PDF/?uri=CELEX:32009H0625\&from=EN. Acesso em: 1 maio 2019.

UNIÃO EUROPEIA. Recomendação do Conselho de 22 de maio de 2018 sobre as Competências Essenciais para a aprendizagem ao longo da vida. Jornal Oficial da União Europeia. C189/01 (04/06/2018). Disponível em: https://eurex.europa.eu/legalcontent/PT/TXT/PDF/?uri=CELEX:32018H0604(01)\&from=EN. Acesso em: 2 set. 2020.

WILSON, C. et al. Alfabetização midiática e informacional: currículo para formação de professores. Brasília: UNESCO, UFTM, 2013.

\section{Márcia Barbosa da Silva}

Doutora em Educação pela Universidade Federal do Rio Grande do Norte com estágio na Universidade do Algarve (PT) e com Pós-doutorado em Literacia Midiática pela Universidade Federal de Juiz de Fora. Professora adjunta da Universidade Estadual de Ponta Grossa, atua no Curso de Pedagogia. Líder e coordenadora do LUME - Laboratório e Núcleo de Estudos e Pesquisas em Mídia e Educação UEPG/CNPq. Participa da Rede Interinstitucional Euroamericana de Investigação sobre Competência Mediática para a Cidadania (ALFAMED). E-mail: marciauepg@gmail.com.

\section{Gabriela Borges}

Professora adjunta na Universidade Federal de Juiz de Fora (UFJF) e atua como professora permanente do Programa de Pós-Graduação em Comunicação, do qual foi coordenadora (20162019). Pós-doutorada pelo CIAC da Universidade do Algarve em Portugal (2005-08, 2019-20), onde atuou como pesquisadora e professora do Mestrado e Doutorado em Comunicação, Cultura e Artes (2005-2012) e ainda atua como colaboradora do Doutorado em Media-Arte Digital. Coordenadora da equipe brasileira da Rede Interinstitucional Euroamericana de Investigação sobre Competência Mediática para a Cidadania (ALFAMED) e do Observatório da Qualidade no Audiovisual e Líder do grupo de pesquisa Comunicação, Arte e Literacia Midiática. E-mail: gabriela.borges0@gmail.com. 


\section{Mônica Fantin}

Doutora em Educação pela Universidade Federal de Santa Catarina com Estágio no Exterior, na UCSC, Milão, Itália. Realizou Pós-Doutorado em Estética no Departamento de Filosofia da Università Cattolica del Sacro Cuore, Milano. Professora Associada do Centro de Educação da Universidade Federal de Santa Catarina, atua no Curso de Pedagogia e no Programa de Pósgraduação em Educação, Linha de Pesquisa Educação e Comunicação. Líder do Grupo de Pesquisa Núcleo Infância, Comunicação, Cultura e Arte, UFSC/CNPq. E-mail: fantin.monica@gmail.com.

\section{Maria Alzira Almeida Pimenta}

Doutora em Educação pela Universidade Estadual de Campinas, Mestre em Artes pela Universidade de São Paulo e graduada em Pedagogia pela Universidade Estadual de Campinas. Integrou o corpo docente do curso de Pós-graduação em Educação da Universidade de Uberaba(UNIUBE). Atualmente, é professora do programa de Pós-graduação em Educação da Universidade de Sorocaba. É associada a ANPED (Associação Nacional de Pós-graduação e Pesquisa em Educação), ao International Study Associationon Teachers and Teaching (ISATT) e ao International Council for Education on Teaching (ICET). Pesquisadora da Rede Interinstitucional Euroamericana de Investigação sobre Competência Mediática para a Cidadania (ALFAMED). E-mail: alzira.pimenta@gmail.com.

\section{Ignácio Aguaded}

Catedrático em Educação e Comunicação na Universidade de Huelva. Preside o Grupo Comunicar, coletivo veterano na España em «Media Literacy». Diretor do Grupo de Investigação «Agora» dentro do Plano Andaluz de Investigação (HUM-648), Diretor do Máster Internacional de Comunicación y Educación (UNIA/UHU) e coordenador na Universidade de Huelva do Programa Interuniversitario de Doctorado en Comunicación (US, UMA, UCA, UHU). Coordena a Rede Interinstitucional Euroamericana de Investigação sobre Competências Mediáticas para a Cidadania (ALFAMED). E-mail: aguaded@uhu.es.

Este artigo é publicado em acesso aberto (Open Access) sob a licença Creative Commons Attribution Non-Commercial (CC-BY-NC), que permite uso, distribuição e reprodução em qualquer meio, sem restrições, desde que sem fins comerciais e que o trabalho original seja corretamente citado.

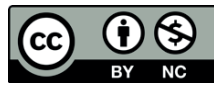

